\title{
Aprender e ensinar design digital no contexto da cibercultura: experiência de ensino com metodologias ativas
}

\author{
Aprendizaje y enseñanza en diseño digital en el contexto de la cultura \\ cibernética: experiencia enseñanza con metodologías activas
}

\section{Learning and teaching digital design in the context of cyberculture: teaching experience with active methodologies}

\author{
Jéssica Rodrigues Esteves ${ }^{1}$ \\ Jair Jonko Araújo ${ }^{2}$
}

\begin{abstract}
Resumo
A cibercultura modificou o pensamento e as relações entre os sujeitos e a tecnologia, impactando também o cenário educacional. Desde o advento da web 2.0, os sujeitos passaram da posição de consumidores de conteúdo para também se tornarem produtores, buscadores e polinizadores desse conteúdo. Com a web 3.0, eles passaram a encontrar informações de maneira mais efetiva, com o auxílio da inteligência artificial. Desta forma, os conhecimentos passaram a ser construídos de forma colaborativa e semântica, o que propiciou a popularização de metodologias ativas - como, por exemplo, a aprendizagem baseada em projetos. Em metodologias ativas o aprendizado ocorre por meio de resolução de problemas e situações reais, na tentativa de simular situações que os estudantes irão vivenciar na vida profissional. A aprendizagem baseada em projetos é um modelo de ensino que estimula os estudantes a desenvolverem trabalhos em grupos, promovendo o questionamento de temas complexos e gerando soluções colaborativas. Neste contexto, o presente artigo apresenta o relato de uma experiência de ensino em aprendizagem baseada em projetos para estudantes do sexto semestre do curso técnico integrado em Comunicação Visual do Instituto Federal Sul-rio-grandense. Partindo de reflexões acerca dos conceitos de cibercultura, tecnologia e design centrado no usuário, os estudantes desenvolverem projetos de interfaces gráficas para aplicativos móveis a partir de temáticas definidas por eles. Em grupos, os estudantes realizaram o mapeamento do problema, as entrevistas, a definição de funcionalidades, a criação de interfaces gráficas, o desenvolvimento de protótipo interativo e a validação com usuários. Esta experiência enfatizou a importância em elaborar propostas de atividades que desenvolvam o pensamento crítico e a motivação dos estudantes nativos digitais, envolvendo-os em contextos de ensino e aprendizagem intrínsecos da cibercultura.
\end{abstract}

Palavras-Chave: Ensino; Cibercultura; Design; Metodologias ativas; Aprendizagem baseada em projetos.

\section{Resumen}

La cibercultura ha cambiado el pensamiento y las relaciones entre las asignaturas y la tecnología, también afectando el entorno educativo. Desde la llegada de la web 2.0, los sujetos han pasado de ser consumidores de contenido a convertirse en productores de contenido, motores de búsqueda y polinizadores. Con la web 3.0, pudieron encontrar contenido de manera más efectiva con la ayuda de la inteligencia artificial. Por lo tanto, el conocimiento comenzó a construirse de manera colaborativa y semántica, lo que condujo a la popularización de metodologías activas en los procesos de enseñanza y aprendizaje, como el aprendizaje basado en proyectos. En las metodologías activas, el aprendizaje ocurre a través de problemas y situaciones reales, en un intento de simular situaciones que los estudiantes experimentarán en su vida profesional. El aprendizaje basado en proyectos es un modelo de enseñanza que alienta a los estudiantes a desarrollar el trabajo en grupo, promoviendo el cuestionamiento de temas complejos y generando soluciones colaborativas. En este contexto, el presente artículo presenta el informe de una experiencia de enseñanza de aprendizaje basada en proyectos para estudiantes del sexto semestre del curso técnico integrado en Comunicación Visual del Instituto Federal de Rio Grande do

\footnotetext{
${ }^{1}$ Mestra em Educação com ênfase em Tecnologias Educacionais; Instituto Federal Sul-rio-grandense - IFSul; Pelotas, Rio Grande do Sul, Brasil; jessica.rodrigues.esteves@gmail.com.

${ }^{2}$ Doutor em Educação pela Universidade Federal de Pelotas - UFPel; professor no Instituto Federal Sul-riograndense - IFSul; Pelotas, Rio Grande do Sul, Brasil; jair.jonko@gmail.com.
} 
Sul. A partir de reflexiones sobre los conceptos de cibercultura, tecnología y diseño centrado en el usuario, los estudiantes desarrollan diseños de interfaz gráfica para aplicaciones móviles basadas en temas definidos por ellos. Los estudiantes trabajaron en grupos para realizar mapeo de problemas, entrevistas, definición de características, diseño de interfaz gráfica de usuario, desarrollo de prototipos interactivos y validación de usuarios. Esta experiencia enfatizó la importancia de desarrollar propuestas para actividades que desarrollen el pensamiento crítico y la motivación de los estudiantes nativos digitales, involucrándolos en los contextos intrínsecos de enseñanza y aprendizaje de la cibercultura.

Palabras clave: enseñanza; Cibercultura; Diseño; Metodologías activas; Aprendizaje basado en proyectos.

\begin{abstract}
Cyberculture has changed thinking and relationships between users and technology, also impacting the educational context. Since the advent of web 2.0, users have moved from being content consumers to becoming content producers, searchers, and pollinators. With web 3.0, they came to find content more effectively with the aid of artificial intelligence. Thus, knowledge began to built-in a collaborative and semantic, which led to the popularization of active methodologies in teaching and learning processes - such as project-based learning. In active learning methodologies occurs through real problems and situations, in an attempt to simulate conditions that students will experience in their professional life. Project-based learning is a teaching model that encourages students to develop group work, promoting the questioning of complex topics, and generating collaborative solutions. This article presents a report of project-based teaching experience in learning for students of the sixth semester of the Integrated Technical Course in Visual Communication of the Federal Institute of Rio Grande do Sul. Starting from reflections on the concepts of cyberculture, technology, and user-centered design, students develop graphical interface designs for mobile applications based on subjects defined by them. Students worked in groups to perform problem mapping, interviews, feature definition, graphical user interface design, interactive prototype development, and user validation. This experience has emphasized the importance of developing proposals for activities that promote critical thinking and motivation of digital native students, involving them in cyberculture intrinsic teaching and learning contexts.
\end{abstract}

Key words: Teaching, Cyberculture, Design, Active learning methodologies, Project-based learning.

\title{
1. Introdução
}

Este artigo tem como objetivo relatar uma prática docente realizada nas disciplinas de Metodologia do Projeto e Informática II, pertencentes ao curso técnico integrado em Comunicação Visual do Instituto Federal Sul-rio-grandense (IFSul), campus Pelotas. A prática tinha como objetivo a criação de interfaces gráficas para aplicativos móveis, envolvendo as duas disciplinas citadas, sendo ambas obrigatórias e pertencentes ao sexto semestre do curso.

O curso técnico integrado em Comunicação Visual é ofertado semestralmente no IFSul para estudantes que já concluíram o ensino fundamental, sendo planejado para garantir tanto a formação do ensino médio quanto a formação profissional técnica. Para ingressar na instituição, os estudantes precisam passar por uma prova de múltipla escolha de caráter eliminatório. De acordo com o catálogo dos $\operatorname{cursos}^{3}$ do IFSul, o perfil profissional do técnico em Comunicação Visual "baseia-se na execução da programação visual de diferentes gêneros e formatos gráficos para peças publicitárias como livros, portais, painéis, folders, jornais". As disciplinas de Metodologia do Projeto e Informática II são obrigatórias e ofertadas no sexto

\footnotetext{
${ }^{3}$ Disponível em: <http://intranet.ifsul.edu.br/catalogo/curso/39>. Acesso em: 31 dez. 2019.
} 
semestre do curso técnico, sendo o primeiro contato dos estudantes com assuntos relativos às etapas projetuais de design. De acordo com a ementa de Metodologia do Projeto, o objetivo da disciplina é "promover a pesquisa do estudo da metodologia no desenvolvimento de projetos de design". Já a disciplina de Informática II trata do ensino do uso de softwares vetoriais, sendo uma continuação da disciplina Informática I.

Ao longo dos anos, os projetos propostos pelas disciplinas tratavam-se da criação de embalagens e identidades visuais, restritas ao design gráfico. O design digital, vertente do design caracterizada pela criação de interfaces digitais interativas, não era uma temática abordada pelas disciplinas. Considerando o contexto da cibercultura e suas influências para a produção de conhecimentos e artefatos, é importante buscar propostas de trabalho que tratem da cultura digital - questões que motivaram esta experiência de ensino.

O artigo está organizado em quatro seções. Na seção atual é apresentada a introdução, contendo as motivações e objetivos do artigo. A segunda seção destinou-se à contextualização do campo de atuação, das disciplinas envolvidas na descrição da prática - contendo o relato das atividades desenvolvidas guiadas pela metodologia do design centrado no usuário (DCU) de Lowdermilk (2013). Na terceira seção foi realizada uma análise reflexiva, buscando a articulação entre a teoria pedagógica e a prática docente, orientada por Lévy (2005), Moran (2018; 2013) e Bender (2012). Por fim, na seção 4, foram apresentas as considerações finais.

\section{Experiência de ensino de design digital: relato da prática docente}

A experiência de ensino foi realizada nas disciplinas de Metodologia do Projeto e Informática II, pertencentes ao sexto semestre do curso técnico integrado em Comunicação Visual, no Instituto Federal Sul-rio-grandense (IFSul), campus Pelotas. De acordo com o Projeto Pedagógico Institucional (IFSUL, 2010), o perfil profissional do técnico em Comunicação Visual é baseado na execução da programação visual de diferentes gêneros e formatos gráficos para peças publicitárias como:

[...] livros, portais, painéis, fôlderes, jornais. Tem também o compromisso de proteger o meio ambiente e trabalhar em equipe. Desenvolve e emprega elementos criativos e estéticos de comunicação visual gráfica. Cria ilustrações, aplica tipografias, desenvolve elementos de identidade visual, aplica e implementa sinalizações. Analisa, interpreta e propõe a produção da identidade visual das peças. Controla, organiza e armazena materiais físicos e digitais da produção gráfica.

Sobre a flexibilidade curricular, a Proposta Pedagógica Curricular (PPC, 2012, p.7) evidencia um currículo "embasado na interdisciplinaridade, no ensino centrado na criatividade e na técnica do saber fazer". O curso também defende uma "formação polivalente e habilidades para buscar soluções sistêmicas para os problemas" (PPC, 2012, p. 8). Outra 
questão evidenciada no documento é a preocupação em formar profissionais que integram as dimensões humanas, técnicas e políticas, a fim de oportunizar a inserção sócio-profissional do sujeito em sociedade.

Com relação à avaliação de desempenho, o PPC (2012, p.11) descreve que será realizada de maneira formal, com a utilização de instrumentos variados de avaliação, tais como "análise de trabalhos, desenvolvimento de projetos, participação em fóruns de discussão, provas e por outras atividades propostas de acordo com a especificidade de cada disciplina". Neste trecho, é possível identificar a variedade de instrumentos de avaliação, sendo o desenvolvimento de projetos um instrumento recorrente entre as disciplinas do curso técnico. Dentre as disciplinas da formação técnica, pode-se inferir que grande parte utilizam principalmente - o desenvolvimento de projetos como instrumento avaliativo.

A fim de inserir os alunos em um contexto de criação de produtos digitais - área que vem crescendo e aumentando as possibilidades de atuação para designers -, foi apresentada uma proposta de trabalho para a disciplina de Metodologia do Projeto a ser desenvolvida interdisciplinarmente com a disciplina de Informática II. A proposta consistia na criação de interfaces gráficas para um aplicativo com temática a ser definida pelo aluno.

Tratando-se de uma disciplina projetual, foi necessário definir uma metodologia de Design para ser utilizada. Dentre as possibilidades, optou-se por utilizar a metodologia do design centrado no usuário (DCU), abordada por Lowdermilk (2013), que pode ser dividida em quatro etapas básicas: [1] identificar requisitos, [2] criar soluções alternativas, [3] construir protótipos testáveis e [4] avaliar com usuários. Os estudantes participaram ativamente no desenvolvimento de cada uma das etapas, utilizando técnicas recomendadas por Lowdermilk (2013), tais como: definição de missão, pesquisa com usuários, análise de similares, criação de storyboards e personas, rabiscoframes, design da interface gráfica, prototipação e testes com usuários. O projeto foi desenvolvido ao longo de 8 semanas, totalizando doze projetos que foram desenvolvidos de forma individual, em duplas e em trios. A faixa de idade dos estudantes era de 17 a 20 anos.

Dada a falta de experiência prévia dos estudantes com o design digital, primeiramente foi preciso introduzi-los a conceitos básicos relativos ao design de interfaces gráficas. Para isso, recorreu-se a autores como Preece, Rogers e Sharp (2013) para abordar conceitos sobre interface gráfica e design de interação; Nielsen (2006) a fim de tratar da definição de usabilidade e sua importância no desenvolvimento de interfaces gráficas; Teixeira (2014) para tratar da experiência do usuário (UX) e suas aplicações; e, por fim, Lowdermilk (2013) que apresenta a metodologia do design centrado no usuário (DCU) por meio de exemplos 
didáticos e objetivos. Neste primeiro momento, foi importante que os estudantes se apropriassem de conceitos e diretrizes para a criação de interfaces gráficas para aplicativos. Por isso, o conteúdo foi apresentado por meio de aulas expositivas e dialogadas e também por atividades que consistiam em análises de interfaces gráficas. Em um segundo momento, os estudantes desenvolveram o projeto a partir das quatro etapas básicas do DCU, que serão descritas e exemplificadas a seguir.

\subsection{Identificar requisitos}

De acordo com a metodologia de DCU (LOWDERMILK, 2013), a etapa de identificar requisitos trata-se de um planejamento estratégico do projeto. Para tal, foi pedido que os estudantes respondessem aos seguintes questionamentos: qual é o propósito do aplicativo? Por que você está desenvolvendo isso? A quem o aplicativo servirá? Como ele agregará valor? A resposta das perguntas originou a missão do aplicativo que, segundo Lowdermilk (2013), representa o propósito geral e a visão do projeto . A seguir, no relato do sujeito 1, é possível compreender a missão e as funcionalidades do aplicativo Pet Point.

O Pet Point é um aplicativo destinado para quem ama e preza pelo bem-estar dos animais. Nele você poderá gerenciar informações sobre seus pets, como o crescimento e o histórico veterinário dele. Você também poderá ajudar um pet a ganhar um novo lar, e encontrar seu mais novo pet - dentro de seu bairro, se você quiser. Além disso, o aplicativo também mostrará o serviço pet que você procura perto de você, sendo possível visualizar informações como horários e valores! (Sujeito 1).

Não foi definida nenhuma temática específica para os aplicativos, mas foi ressaltado que os estudantes pensassem em um produto que pudesse facilitar tarefas diárias ou conscientizar as pessoas sobre uma causa. Dessa forma, surgiram temáticas variadas relacionadas ao comércio, à comunicação, à conscientização, ao entretenimento e à jogos. Definida a missão, os estudantes realizaram uma análise de similares a partir de uma busca por aplicativos semelhantes na Apple Store e na Google Play. Com a análise, foi possível verificar as principais funcionalidades e os pontos positivos e negativos dos aplicativos concorrentes. Observou-se que, durante a análise dos aplicativos similares, os estudantes utilizaram termos que foram apresentados em aula, classificando as interfaces com terminologias específicas da área do design digital, tais como "boa usabilidade" ou "problemas de interação" - o que demonstrou o conhecimento deles sobre os conteúdos estudados.

A análise de similares foi um exercício fundamental para melhorar compreensão quanto ao design de interfaces para dispositivos móveis. Dando continuidade, prosseguiu-se 
para a definição dos requisitos funcionais e do usuário, tendo como base a análise de similares e as funcionalidades propostas na missão do aplicativo.

\subsection{Criar soluções alternativas}

Nesta etapa, foram delimitadas as restrições e possibilidades do projeto, por meio de uma narrativa sobre como o aplicativo poderá ser utilizado. Para tal, foram realizadas entrevistas qualitativas com possíveis usuários dos aplicativos, criação de storyboards e definição de proto-personas. Ambas técnicas auxiliaram os estudantes a refinarem a ideia inicial do aplicativo, aprimorando as funcionalidades pré-definidas e adicionando outras relevantes.

As entrevistas qualitativas foram realizadas de forma presencial com o número mínimo de cinco usuários. Em um primeiro momento, os estudantes demonstraram um certo receio ao fato de precisarem entrevistar cinco pessoas desconhecidas. Contudo, após a atividade, relataram o quanto foi importante conversar com os usuários potenciais e obter respostas além das perguntas abertas pré-estabelecidas. Nesta etapa, também foi possível coletar informações sobre as preferências dos usuários, como: produtos preferidos, tarefas que lhe deixam frustrados, gostos pessoais e faixa etária. Essas informações auxiliaram os estudantes na construção de personas, sendo a próxima atividade desta etapa.

Segundo Lowdermilk (2013, p.73), persona é um "personagem de ficção que consiste na personificação de seus usuários reais" e auxiliam a melhorar a narrativa e contar a história do aplicativo. De acordo com Gothelf (2013), para a criação de personas são necessários meses de entrevistas e alto investimento, o que torna o processo inviável para algumas empresas. Assim, o autor apresenta uma alternativa ao processo, a qual chama de protopersonas, definindo como uma variante simples à criação de personas. Para Gothelf (2013), as proto-personas são baseadas em suposições e hipóteses, ajudando a definir quem irá utilizar o produto e por que fará o uso dele. Para esta atividade, foi utilizado o modelo para criação de personas do autor, em que as informações são divididas em quatro quadrantes: [1] desenho, nome e informações gerais; [2] comportamentos; [3] dores e necessidades; [4] potenciais soluções. Seguindo a recomendação de Gothelf (2013), os estudantes esboçaram as personas utilizando papel e caneta, tornando o processo mais ágil. Para o aplicativo Beleza Natural, foi criada a proto-persona Vitória. De acordo com as informações descritas no modelo, os estudantes descreveram Vitória da seguinte forma:

1) Informações: Vitória, 43 anos, bibliotecária, mora sozinha. 
2) Comportamentos: usa cosméticos todos os dias, pensa muito sobre os malefícios químicos contidos nos cosméticos, interessa-se por tratamentos naturais, tem dificuldades de entender as informações contidas nos rótulos dos cosméticos;

3) Dores e Necessidades: entender as informações dos rótulos, aprender coisas novas, ser mais saudável, cuidar da beleza de forma mais natural, prevenir problemas de saúde.

4) Potenciais Soluções: aplicativo móvel para ajudar a entender componentes químicos em produtos de beleza, adicionar funcionalidades que ajudem o usuário a entender o rótulo de produtos de beleza, adicionar informações sobre vida saudável.

(Sujeitos 3 e 4).

A partir da descrição dos sujeitos 3 e 4, é compreendido que o projeto tem como objetivo criar um aplicativo que ajuda a identificar ingredientes químicos tóxicos encontrados em produtos de beleza. Observa-se que os sujeitos relataram os problemas enfrentados pela persona ao tentar ler os rótulos dos produtos, a falta de entendimento do conteúdo dos rótulos e a preocupação dela com a saúde devido a quantidade de químicos contidos nos cosméticos. Todas essas suposições ajudaram a delimitar as funcionalidades do aplicativo, auxiliando também a identificar outras possibilidades da aplicação.

Após a criação das proto-personas, prosseguiu-se para o desenvolvimento dos cenários, criados por meio de storyboards. Estes são uma sequência em quadrinhos utilizada no cinema, em que o processo consiste na organização de uma série de painéis ilustrados para representar o fluxo de uma cena (KALBACH, 2016). De acordo com Lowdermilk (2013, p.76), ao utilizar cenários torna-se possível "explorar como o aplicativo responderá (ou não) às necessidades dos usuários". Kalbach (2016) afirma que a criação de storyboards ajuda a colocar as personas em ação, inserindo contrastes e contextos em um mesmo local. O autor acredita que os storyboards são um tipo de narrativa visual pois "descrevem o passo a passo de uma interação ou problema, promovendo um entendimento compartilhado de visão" (KALBACH, p. 198). Por isso, foi pedido que os estudantes desenhassem um storyboard que possuísse personagens, um ambiente e uma tarefa a ser realizada, mostrando por que o personagem deveria utilizar o aplicativo para concluir a tarefa e como esse objetivo seria alcançado. O roteiro de um storyboard criado pelos estudantes é apresentado na Figura 1, onde foram narradas as motivações e a missão do aplicativo VeganUp. 


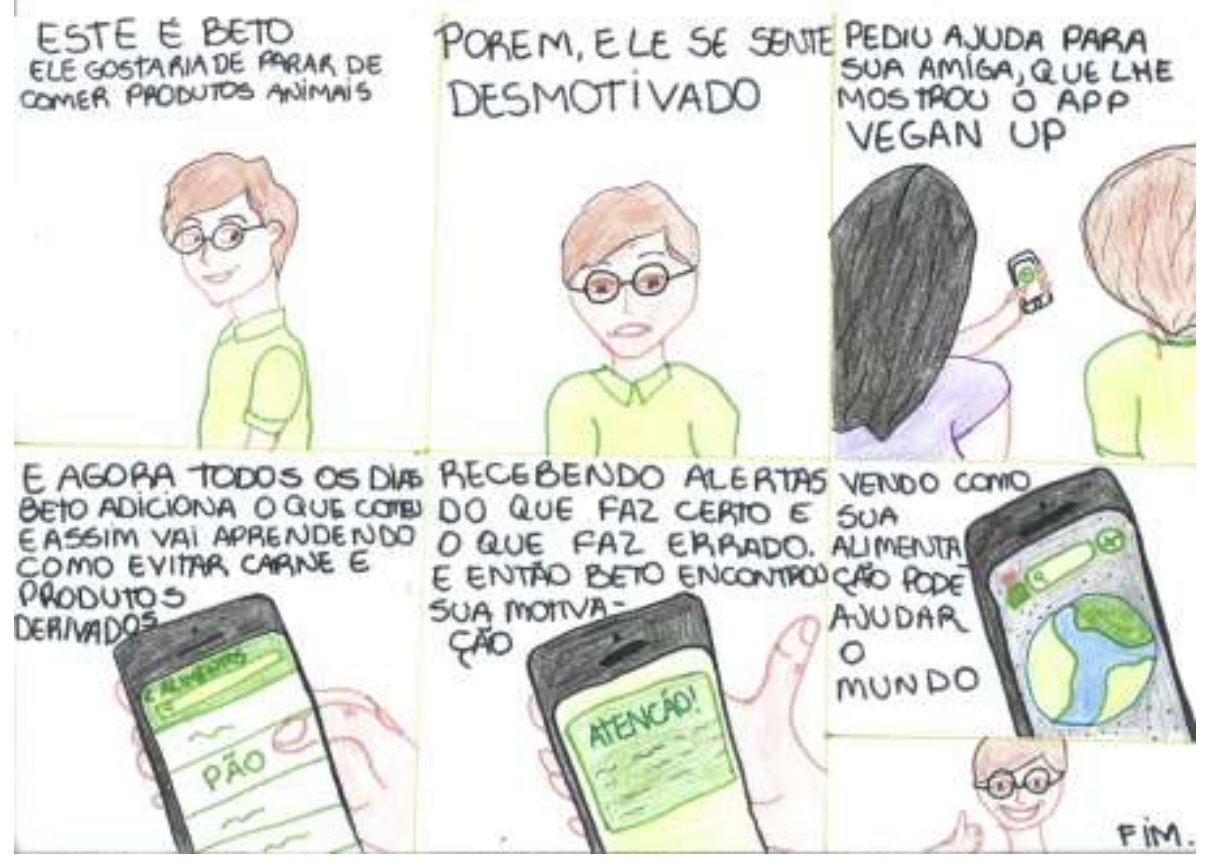

Figura 1: Storyboard para o aplicativo VeganUp.

Fonte: Sujeitos 5 e 6.

Na Figura 1, é possível observar as motivações do usuário (Beto) para utilizar o aplicativo VeganUp no seu dia-a-dia. O storyboard é acompanhada de desenhos, fazendo com que seja possível observar o cenário em que os personagens estão realizando a tarefa. Assim, após a delimitação das soluções a partir de narrativas visuais e textuais, prosseguiu-se para a etapa de prototipação.

\subsection{Construir protótipos testáveis}

Esta etapa foi uma das mais desafiadoras de todo o projeto, pois os estudantes não possuíam experiências com o design digital. Portanto, foi necessário ambientá-los nesse contexto para que pudessem produzir interfaces gráficas que apresentassem boa usabilidade seguindo as recomendações de Nielsen (2007).

Para iniciar o processo, os estudantes criaram wireframes de baixa fidelidade em papel, popularmente conhecidos pelo termo rabiscoframe - que, de acordo com Teixeira (2014, p. 112), trata-se de uma "mistura bem humorada" do termo sketch com o termo já conhecido wireframe. Para o autor, os rabiscoframes servem para que designers e desenvolvedores entendam o que se espera da interface, tornando o processo de wireframing mais rápido e podendo eliminar a necessidade de wireframes mais detalhados.

A grande maioria dos estudantes optou por desenhar os rabiscoframes e relataram que o exercício serviu de suporte para a criação da interface gráfica, apresentando poucas diferenças estruturais com relação a interface final. Um pequeno grupo preferiu criar 
diretamente no computador, pois alegaram que seria mais fácil para construir a interface. Um exemplo de rabiscoframe dos sujeitos 7 e 8 é apresentado na Figura 2, onde é possível observar o fluxo das telas, bem como a organização estrutural dos elementos da interface.

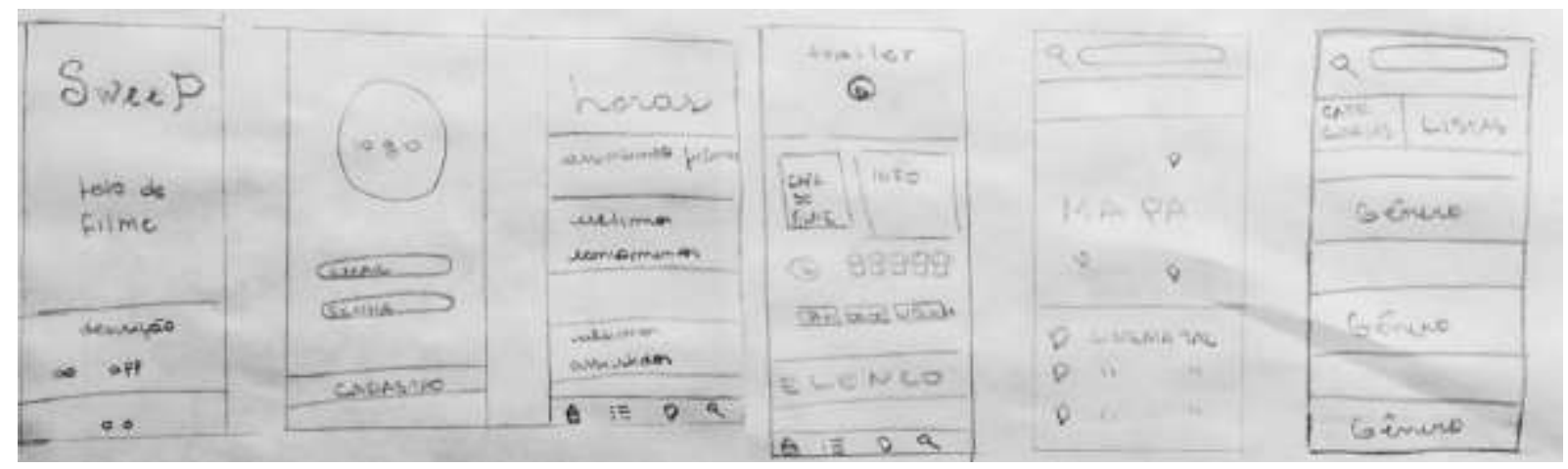

Figura 2: Rabiscoframe para o aplicativo Sweep.

Fonte: Sujeitos 7 e 8.

Após a definição dos wireframes, partiu-se para a criação da interface gráfica do aplicativo a partir do referencial do Google Material Design ${ }^{4}$. De acordo com Jitkoff (2016), o Material Design foi concebido para servir como uma metáfora para racionalizar o design e implementação, fornecendo aos designers um conjunto de princípios para criação de interfaces digitais. Logo, a utilização deste referencial auxiliou os estudantes no desenvolvimento do projeto, fornecendo conteúdo relativo a utilização de tipografia, cor, ícones e interações. Nesta etapa, os estudantes também definiram o ícone do aplicativo, os ícones de navegação e as interfaces gráficas principais dos aplicativos. Após a criação das interfaces, foi utilizado o software online Invision ${ }^{5}$ para construir o protótipo navegável do aplicativo e, assim, fosse possível realizar os testes de usabilidade - o que corresponde a próxima etapa.

\subsection{Avaliar com usuários}

Nesta etapa, os estudantes conduziram testes de usabilidade com base no método Think-Aloud que solicita que os usuários verbalizem suas ações e intenções durante a utilização de um produto, narrando as experiências como se estivessem "pensando alto" (NIELSEN, 2012). Seguindo as recomendações de Nielsen (2000), o teste foi realizado com cinco usuários, sendo esse número considerado o ideal para que se possa obter resultados relevantes.

\footnotetext{
${ }^{4}$ Disponível em: < https://material.io/guidelines/>. Acesso em: 30 dez. 2019.

${ }^{5}$ Disponível em: < https://www.invisionapp.com/>. Acesso em: 30 dez. 2019.
} 
As descrições dos testes de usabilidades foram documentadas pelos estudantes e, após os testes, foram realizadas modificações nos protótipos. De modo geral, as principais alterações sugeridas pelos usuários eram com relação a disposição dos elementos nos menus e identificação dos ícones, como pode ser identificado no relato a seguir dos sujeitos 9 e 10.

Depois da apresentação da simulação do aplicativo para os visitantes, resolvi fazer uma pequena mudança na última tela. Vi que vários usuários teriam dificuldade em voltar às opções de entrada pois não havia um botão com a opção de acesso à tela de boas vindas. Apliquei então, o ícone de uma porta, que levará o usuário à terceira tela novamente (Sujeitos 9 e 10).

$\mathrm{O}$ teste de usabilidade possibilitou que os estudantes aprimorassem o seu conhecimento acerca da área de experiência do usuário, aprendendo a identificar inconsistências e percebendo a importância de feedbacks para melhor delimitação da proposta. Após a etapa, os estudantes tiveram uma semana para realizar alterações. Na entrega final, os estudantes apresentaram todo o processo de criação do aplicativo - desde a concepção até a prototipação, evidenciando todas as melhorias que foram realizadas após o teste de usabilidade.

\subsection{Resultados da prática: aplicativos criados}

Ao fim da proposta, os aplicativos foram classificados em cinco categorias, sendo elas: [1] comercial, [2] comunicação, [3] conscientização, [4] entretenimento e [5] jogos, disponíveis na Figura 3. O critério de classificação foi com base no objetivo principal e missão de cada projeto.

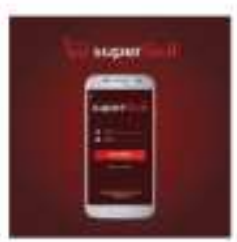

COMERCIAL

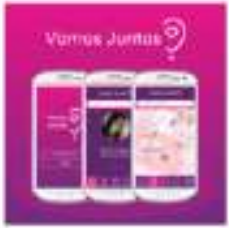

COMUNICACÃO
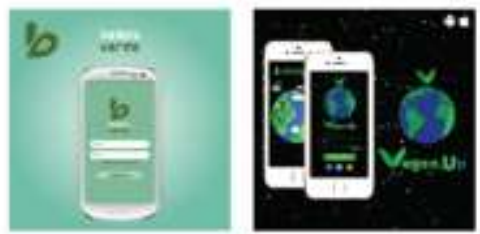

CONSCIENTIZACAĀO

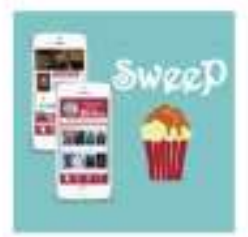

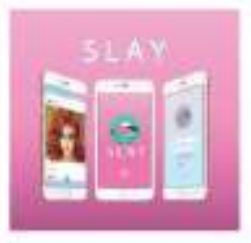

ENTRETENIMENTO
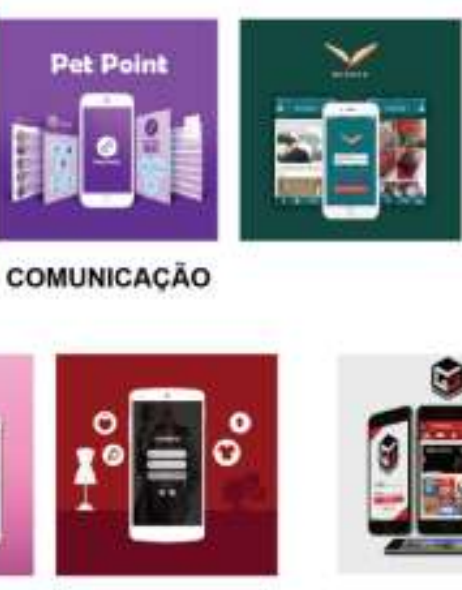

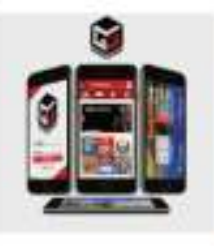

Jogos

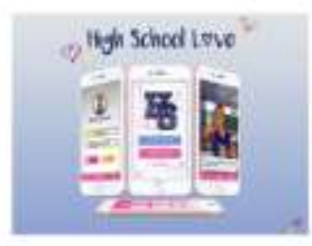

Figura 3: Aplicativos criados pelos estudantes.

Fonte: Sujeitos 1 a 18. 


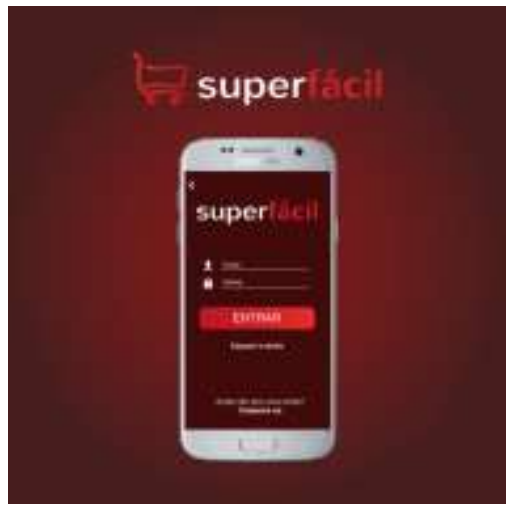

Figura 4: Aplicativo Superfácil.

Fonte: Sujeitos 9, 10 e 11.

$\mathrm{Na}$ categoria comercial, classificam-se os aplicativos que tinham como objetivo principal a compra e venda de produtos. Apenas um aplicativo desenvolvido por um grupo de estudantes foi classificado nessa categoria - aplicativo Superfácil - disponível na Figura 4. O objetivo deste aplicativo é funcionar como um e-commerce para compra de produtos de uso diário.
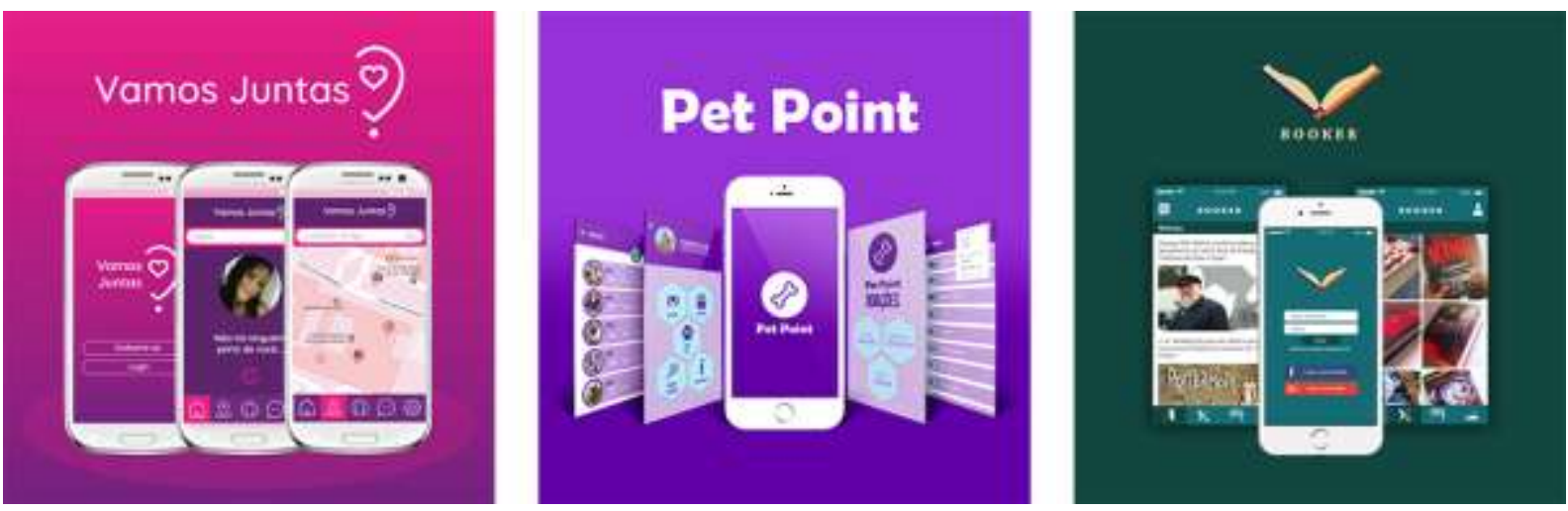

Figura 5: Aplicativos Vamos Juntas?, Pet Point e Booker.

Fonte: Sujeitos 1 a 18 .

Em comunicação, organizaram-se aplicativos que tinham como missão facilitar a troca de informações entre usuários. Nesta categoria, foram identificados três aplicativos, sendo eles: Booker, Pet Point e Vamos Juntas? - disponíveis na Figura 5. O primeiro tem como objetivo a troca e classificação de livros; já o segundo tem a missão de facilitar o processo de adoção de animais; por último, o terceiro visa unir mulheres para percorrerem caminhos diários em companhia, com o objetivo de aumentar a segurança.

A categoria conscientização engloba projetos que foram concebidos com o objetivo de disseminar uma ideia, conforme foi proposto pelos aplicativos VeganUp e Beleza Verde. 
Na Figura 6 é possível visualizar as interfaces gráficas dos aplicativos da categoria. Sob diferentes perspectivas, esses projetos visam, respectivamente, conscientizar sobre a importância da alimentação vegana e atentar os consumidores quanto a quantidade de ingredientes tóxicos utilizados em produtos de beleza.
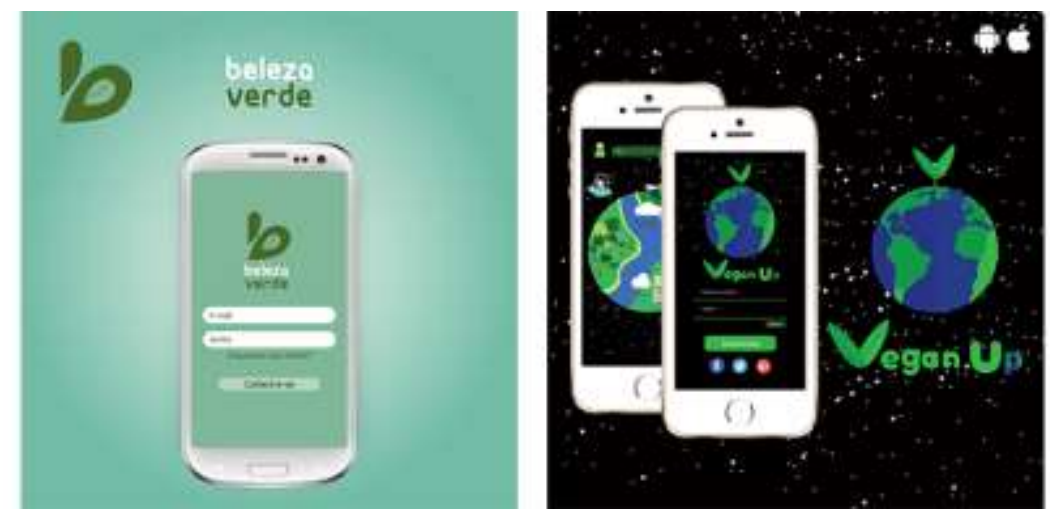

Figura 6: Aplicativos Beleza Verde e VeganUp

Fonte: Sujeitos 1 a 18.

SweeP, Slay e Cabidário - disponíveis na Figura 7 - são aplicativos que foram inseridos na categoria entretenimento. Ambos projetos visam ensinar e entreter os usuários sob diferentes enfoques. O aplicativo SweeP possibilita que usuários possam classificar filmes e séries, contabilizando o tempo gasto para assisti-los; já o Slay tem como público alvo pessoas que admiram a arte drag queen e gostariam de aprender a maquiar-se como uma drag; por último, o Cabidário possibilita que usuários montem seu armário virtual e recebam dicas de como combinar roupas e acessórios.
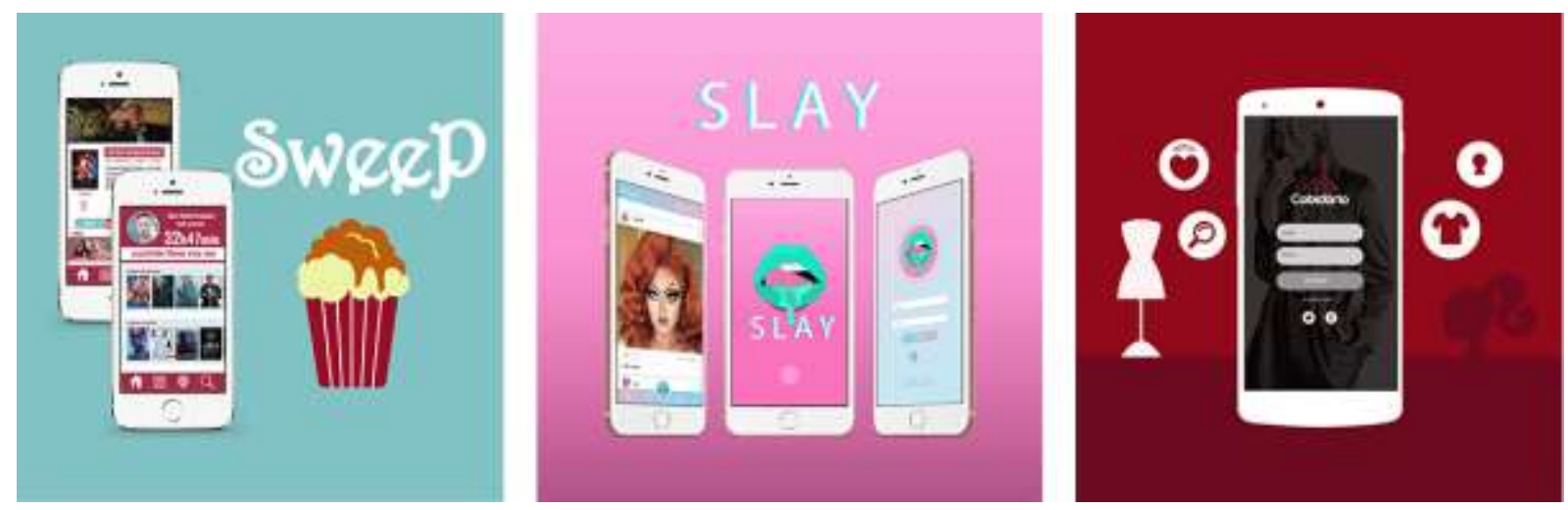

Figura 7: Aplicativos SweeP, Slay e Cabidário.

Fonte: Sujeitos 1 a 18 . 
Por fim, na categoria jogos, identificaram-se dois aplicativos - Good Games e High School Love, disponíveis na Figura 8. O primeiro trata-se de um sistema de assinatura de jogos, onde assinantes possuiriam acesso a um grande leque de jogos, além de jogar com amigos e compartilhar momentos do jogo; já o segundo classifica-se como um dating gamejogo de paquera -, permitindo que usuários possam interagir na narrativa do personagem principal, por meio por meio de diálogos e escolhas que determinam o rumo da história.
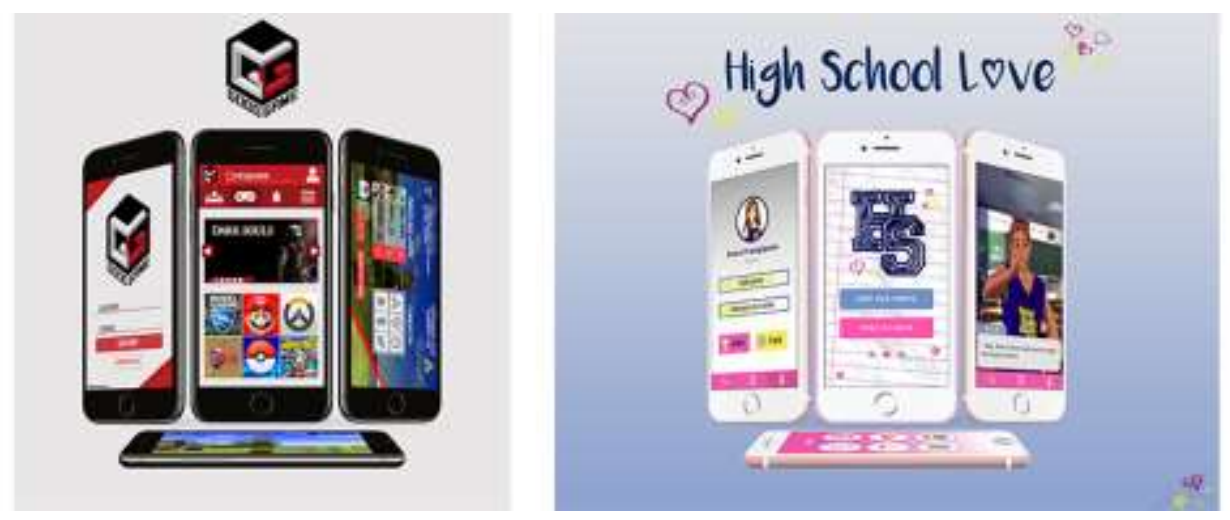

Figura 8: Aplicativos Good Games e High School Love.

Fonte: Sujeitos 1 a 18 .

De forma geral, ambos os aplicativos atenderam satisfatoriamente aos requisitos de design de interfaces para dispositivos móveis, obedecendo as recomendações de estrutura, organização, uso de tipografia e ícones. Quanto a temática dos projetos, foi interessante analisar que os estudantes partiram de temas que permeiam o seu universo, seja na busca por uma dieta alimentar mais saudável - como o aplicativo VeganUp -, na otimização de compras do supermercado - como no aplicativo Superfácil - ou ainda baseado em sua experiência com jogos para dispositivos móveis - como no aplicativo Good Game.

\section{Aprender e ensinar no contexto da cibercultura: análise reflexiva}

Ao promover esta experiência de ensino e aprendizagem com estudantes do curso técnico em Comunicação Visual procurei enfatizar a importância do processo de criação, mostrando-o como algo inerente na profissão de designer, independente do meio para qual se produz - seja físico ou digital. A decisão em produzir um produto digital - aplicativo - ao invés de um produto físico deu-se devido à busca em propor atividades que pudessem envolver e despertar a curiosidade dos estudantes nativos digitais (PRENSKY, 2001), além de mostrar outras possibilidades de atuação do profissional técnico em Comunicação Visual considerando o contexto da cibercultura. 
Para Lévy (2005), a cibercultura é a cultura que surgiu - ou está surgindo - a partir do uso da rede de computadores e de outros suportes tecnológicos - como, por exemplo, os smartphones - através da comunicação virtual, da indústria do entretenimento e do comércio eletrônico, no qual se configura o presente. Sendo o técnico em Comunicação Visual responsável por produzir peças para diferentes meios - como livros, portais, painéis, fôlderes, jornais - é necessário que esses profissionais também saibam produzir materiais para o meio digital, como interfaces gráficas para dispositivos móveis - fato que motivou essa experiência de ensino.

A cibercultura afeta também a educação, de modo que os conhecimentos não são produzidos e compreendidos da mesma forma que anteriormente, pois estamos todos imersos na cultura digital. Lévy (2005) relata uma mudança necessária nos processos de ensino e aprendizagem, pois

o que é preciso aprender não pode mais ser planejado nem precisamente definido com antecedência. [...] Devemos construir novos modelos do espaço dos conhecimentos. No lugar de representação em escalas lineares e paralelas, em pirâmides estruturadas em 'níveis', organizadas pela noção de pré-requisitos e convergindo para saberes 'superiores', a partir de agora devemos preferir a imagem em espaços de conhecimentos emergentes, abertos, contínuos, em fluxo, não lineares, se reorganizando de acordo com os objetivos ou os contextos, nos quais cada um ocupa posição singular e evolutiva (LÉVY, 2005, p. 158, grifo nosso).

Desta forma, os conhecimentos passam a ser construídos de forma colaborativa, fazendo com que o professor deixe de ser o centralizador do conhecimento e torne-se curador ou ainda orientador - questões que propiciaram a popularização de metodologias ativas nos processos de ensino e aprendizagem.

De acordo com Moran (2013) as metodologias ativas são o caminho para que possamos avançar no conhecimento profundo, nas competências emocionais e em novas práticas pedagógicas. Segundo o autor, as escolas estão mudando para modelos mais centrados em "aprender ativamente com problemas reais, desafios relevantes, jogos, atividades e leituras, valores fundamentais, combinando tempos individuais e tempos coletivos; projetos pessoas de vida e de aprendizagem e projetos em grupo" (MORAN, 2013, p. 67).

No contexto atual, em que a tecnologia digital permeia as relações cotidianas, as metodologias ativas se expressam por meio de modelos de ensino híbridos, blended, entre outras possíveis combinações (MORAN, 2013). Dentre os modelos existentes, a aprendizagem baseada em projetos (ABP) é "uma metodologia de aprendizagem em que os estudantes se envolvem com tarefas e desafios para resolver um problema ou desenvolver um 
projeto que tenha ligação com a sua vida fora da sala de aula” (MORAN, 2018, p. 5). Para Bender (2012, p. 25), a aprendizagem baseada em projetos:

[...] pode ser definida pela utilização de projetos autênticos e realistas, baseados em uma questão, tarefa ou problema altamente motivador e envolvente, para ensinar conteúdos acadêmicos aos estudantes no contexto do trabalho cooperativo para a resolução de problemas.

$\mathrm{O}$ uso da $\mathrm{ABP}$ faz com que os estudantes lidem com questões interdisciplinares, tomem decisões, ajam sozinhos e em equipe. Nos projetos, os estudantes desenvolvem também habilidades de pensamento crítico e criativo, além da percepção de que existem diferentes formas de completar uma tarefa - o que, segundo Bender (2012) e Moran (2018; 2013), são competências necessárias para o século XXI.

Em uma era em que as mídias digitais permitem a comunicação instantânea e há disponibilidade de informações quase ilimitada na internet, os defensores da ABP sugerem que produzir sentido a partir da grande quantidade virtual de informações caóticas é exatamente o tipo de construção de conhecimento que todo aluno no mundo de hoje precisa dominar (BENDER, 2012, p. 25).

Dado o contexto, a ABP foi utilizada como estratégia de ensino para as disciplinas de Metodologia do Projeto e Informática II no curso técnico integrado em Comunicação Visual, a fim de tornar os estudantes sujeitos ativos no processo de ensino e aprendizagem.

A utilização do design centrado no usuário (DCU) para uma prática docente orientada pela ABP possibilitou que os estudantes auxiliassem uns aos outros no desenvolvimento de seus projetos, ainda que alguns projetos tenham sido desenvolvidos individualmente. Ao transitar por todas as etapas do DCU, os estudantes se apropriaram de conhecimentos além do proposto pela ementa da disciplina de Metodologia de Projeto, compreendendo a importância de dialogar com usuários, testar o projeto, ajustá-lo e testar novamente. Durante as oito semanas de projeto, a sala de aula tornou-se um grande laboratório de troca de conhecimentos, fazendo com que alunos e professores atuassem ativamente para a construção do projeto. É importante destacar também o meu papel enquanto docente, que assumi a postura de orientadora. Ao invés de expor conteúdos ou apontar soluções, meu papel foi o de auxiliar os alunos a "irem além de onde conseguiriam ir sozinhos, motivando, questionando, orientando" (MORAN, 2018, p.4).

Este projeto foi o primeiro trabalho de design de interfaces gráficas criado pelos estudantes, que partiu de uma temática investigada e delimitada por eles mesmos. A liberdade para delimitação do tema do aplicativo foi um fator primordial para aumentar o engajamento e a motivação com o projeto. De forma geral, todos os estudantes mostraram-se satisfeitos e orgulhosos dos projetos desenvolvidos, ressaltando que, pela primeira vez, foram tratados 
como designers em formação e não como meros estudantes do ensino técnico integrado. Muitos estudantes ainda relataram que este projeto acabou por motivá-los a continuar os estudos na área de design de interfaces e design de interação.

Por fim, é importante destacar que as técnicas de DCU utilizadas pelos estudantes tais como pesquisa, storyboard, análise de similares, proto-personas e testes - não se limitam apenas a um projeto de design, pois o pensamento crítico desenvolvido por meio desse processo pode ser aplicado em qualquer área do conhecimento.

\section{Considerações finais}

Neste artigo foi apresentado o relato de uma experiência de ensino com o uso da aprendizagem baseada em projetos para o ensino de design digital no curso técnico integrado em Comunicação Visual. A experiência de ensino tinha como objetivo a criação de interfaces gráficas para aplicativos, envolvendo duas disciplinas obrigatórias - Metodologia do Projeto e Informática II.

A aprendizagem baseada em projetos (ABP) foi utilizada por meio de uma metodologia projetual da área do Design - o design centrado no usuário (DCU) - dividida em quatro etapas principais, compreendendo atividades distintas. Ao fim do projeto, compreendeu-se que a experiência de ensino com a ABP possibilitou que os estudantes se tornassem sujeitos ativos no processo de ensino e aprendizagem, capazes de desenvolver projetos autênticos, realistas e profissionais. A experiência também evidenciou que o uso da ABP torna o processo de ensino e aprendizagem de conteúdos acadêmicos motivador, tendo em vista que os alunos são inseridos em um contexto de trabalho cooperativo para a resolução de um problema e, para isso, precisam compreender os conteúdos teóricos e aplicá-los em um projeto prático.

Por fim, ressalta-se a importância em desenvolver estratégias de ensino e aprendizagem que envolvam os estudantes, de modo a despertar seus interesses e curiosidades. Neste contexto, a ABP aplicada ao ensino de design é uma estratégia de ensino, oriunda das metodologias ativas, que pode colocar os estudantes para produzirem conhecimentos por meio da pesquisa, análise e criação de artefatos e/ou objetos.

\section{Referências}

BENDER, W. N. Aprendizagem baseada em projetos: educação diferenciada para o século XXI. Porto Alegre: Penso, 2014. 
GOTHELF, J. Lean UX: Applying lean principles to improve user experience. Sebastopol, CA: O'Reilly Media, Inc., 2013.

INSTITUTO FEDERAL DE EDUCAÇÃO, CIÊNCIA E TECNOLOGIA SULRIOGRANDENSE. Projeto pedagógico institucional: uma construção participativa. Pelotas, RS: $\quad$ mar. 2010. Disponível em: <http://www.ifsul.edu.br/images/documentos/projeto_pedagogico_institucional__.pdf >. Acesso em: 29 nov. de 2019.

JITKOFF, N. Design Is Never Done: Material Design's new suite of tools and guidelines all in one place. 20 out. 2016. Disponível em: <https://design.google/library/design-neverdone/> Acesso em: 26 out. 2019.

KALBACH, J. Mapping experiences: A complete guide to creating value through journeys, blueprints, and diagrams. Sebastopol, CA: O'Reilly Media, Inc., 2016.

LÉVY, P. Cibercultura. 5. ed. São Paulo: Editora 34 LTDA, 2005.

LOWDERMILK, T. Design Centrado no Usuário: Um guia para o desenvolvimento de aplicativos amigáveis. São Paulo: Novatec, 2013.

MORAN, J. Metodologias ativas para uma aprendizagem mais profunda. Educatrix. Dossiê Currículo, São Paulo: Moderna, a. 7, n. 12, p. 66-69, 2013. Disponível em: $<$ https://www.moderna.com.br/educatrix/ed13/educatrix13.html?pag=66>. Acesso em: 22 nov. 2019.

MORAN, J. Metodologias ativas para uma aprendizagem mais profunda. In: BACICH, L.; MORAN, J. (Org.). Metodologias ativas para uma educação inovadora: uma abordagem teórico-prática. Porto Alegre: Penso, 2018. p. 1 - 25.

NIELSEN, J. Thinking Aloud: The \#1 Usability Tool . 16 jan. 2012. In: Nielsen Norman Group. Disponível em: <https://www.nngroup.com/articles/thinking-aloud-the-1-usabilitytool/> Acesso em: 8 jul. 2019.

NIELSEN, J. Usabilidade na web. Rio de Janeiro, RJ: Elsevier, 2007.

NIELSEN, J. Why You Only Need to Test with 5 Users. In: Nielsen Norman Group. 19 mar. 2000. Disponível em: <https://www.nngroup.com/articles/why-you-only-need-to-test-with-5users/> Acesso em: 10 jul. 2019.

PREECE, J.; ROGERS, Y.; SHARP, H. Design de interação: além da interação homemcomputador. Porto Alegre, RS: Bookman, 2005.

PROPOSTA PEDAGÓGICA CURRICULAR. Curso Técnico em Comunicação Visual (forma integrada). Pelotas, 2012. Disponível em: < http://intranet.ifsul.edu.br/catalogo/curso/39>. Acesso em: 21 nov. 2019.

PRENSKY, M. Digital natives, digital immigrants, part I. On the Horizon. Lincoln: NCB University Press, v. 9, nº 5, 2001. 
RELACult - Revista Latino-Americana de Estudos em Cultura e Sociedade

Revista Latinoamericana de Estudios en Cultura y Sociedad | Latin American Journal of Studies in Culture and Society V. 06, ed.especial, mar., 2020, artigo $\mathrm{n}^{\circ} 1750$ | claec.org/relacult | e-ISSN: 2525-7870

TEIXEIRA, F. Introdução e Boas Práticas em UX Design. São Paulo: Casa do código, 2014. 